\title{
Uso do geoprocessamento na delimitação de unidades geoambientais do município de Icapuí - CE.
}

Use of GIS in the delimitation of geo-environmental units in the city of Icapuí - CE.

\author{
VIEIRA'1, L. F.; MEIRELES ${ }^{2}$, A. J. A.
}

leticiageoufc@gmail.com

\begin{abstract}
Resumo
Este artigo provém de uma pesquisa de Iniciação Cientifica que o foco era estudar a planície costeira de Icapuí, por meio dessa pesquisa iniciou-se o trabalho de identificar as unidades geoambientais do município, empregando o sensoriamento remoto e o geoprocessamento para identificar e delimitar essas unidades. A planície costeira de Icapuí é composta por várias morfologias, que foram originadas por processos eustáticos de flutuações marinhas desde o cretáceo. Esses processos deixaram evidencias morfológicas que podem ser constatadas principalmente nos terraços marinhos. Os resultados obtidos por meio de geoprocessamento foram satisfatórios para o que foi proposto, sendo assim, evidenciando todo o relevo e suas unidades do município.
\end{abstract}

Palavras-chave: Unidades geoambientais, Icapuí, Geoprocessamento.

\begin{abstract}
This article comes from a Scientific Initiation research focus was to study the coastal plain of Icapuí, through this research began work to identify the geo-environmental units in the city, using remote sensing and GIS to identify and define these units. The coastal plain of Icapuí is composed of various morphologies, which were caused by eustatic processes of sea level fluctuations from the cretaceous. These processes have left morphological evidence that can be observed mainly in marine terraces. The results obtained by GIS were satisfactory to what has been proposed, therefore, evidencing all its raised and municipal units.
\end{abstract}

Keywords: Geo-environmental units, Icapuí, GIS.

\section{INTRODUÇÃO}

Este artigo provém dos resultados de uma bolsa de Iniciação Cientifica PIBIC/CNPq da Universidade Federal do Ceará com o título: Evolução espaço-temporal da planície costeira de Icapuí: erosão da faixa de praia e dunas móveis. Orientada pelo professor Jeovah Meireles. Um dos objetivos dessa pesquisa foram identificar e analisar espaço-temporalmente os aspectos geomorfológicos da planície costeira através das ferramentas do geoprocessamento. Esse objetivo em especifico foi o incentivo para esse artigo que tem como foco principal o mapeamento das unidades geoambientais do município de Icapuí.

Localizado no extremo leste do litoral cearense, fazendo divisa com o Estado do Rio Grande do Norte, Icapuí tem aproximadamente $420 \mathrm{~km}^{2}$ em área e $46 \mathrm{~km}$ de linha de costa. De acordo com a Funceme, o clima é predominantemente sub-úmido seco e ventos de direção E-SE. Em Icapuí nós encontramos uma planície litorânea com elevado número de feições morfológicos: campos de dunas fixas e móveis, falésias vivas e paleofalésias, terraços marinhos, planície fluviomarinha, delta de maré e demais morfologias que serão discutidas no decorrer deste artigo. Essas feições 
morfológicas foram originadas a partir de flutuações do nível do mar, mudanças eustáticas acontecidas principalmente durante o período plio-pleistoceno no Quaternário e, possivelmente eventos neotectônicos (SOUSA 2003). Foram constatadas várias evidencias dos dois últimos níveis mais altos do mar, além disso, outras oscilações marinhas na região desde o Cretáceo (MEIRELES, 1991). Os diversos eventos transgressivos e regressivos produziram profundas alterações na dinâmica terrestre, acarretando, no nosso caso, um complexo conjunto de morfologias e ecossistemas (MEIRELES, 2005).

Nesse artigo será proposto uma classificação de unidades geoambientais do município de Icapuí através do auxílio do sensoriamento remoto e do geoprocessamento. Foram utilizadas imagens de satélite Landsat 8 e feita uma composição RGB - 543 e imagem de radar SRTM 30 metros. Através dos resultados obtidos por meio do geoprocessamento, poderemos constatar e delimitar as unidades geoambientais.

É preciso salientar também que em Icapuí há problemas ambientais, que devem ser vistos com importância, e que auxiliados de um diagnóstico ambiental, a sociedade e o Estado possam fazer e executar um planejamento ambiental contextualizado e eficiente, no qual possibilite a melhoria na qualidade de vida das comunidades litorâneas. A exemplo do uso do geoprocessamento e sensoriamento remoto com aplicabilidade para o planejamento ambiental temos o trabalho de Souza (2016) que elabora um diagnóstico e uma projeção dos cenários litorâneos de Icapuí, proporcionando ao planejamento ambiental do município.

\section{METODOLOGIA}

A metodologia empregada nesse trabalho consistiu basicamente em uma análise de imagens de satélite e radar utilizando Sistema de Informação Geografia ArcGis 10.4, Global Mapper 16 e um software de processamento de imagens (PDI) ENVI 5.3. As imagens de satélite Landsat 8 e imagem de radar Shuttle Radar Topography Mission (SRTM) com resolução de 30 metros, foram coletados gratuitamente pelo Serviço Geológico dos Estados Unidos pelo site http://earthexplorer.usgs.gov/. O georreferenciamento destas imagens considerou o Datum geocêntrico SIRGAS 2000, e o sistema de projeção Universal Transversa de Mercator (UTM) na zona 24 Sul.

Após a sistematização desses dados em um ambiente SIG, foram feitas aplicações que geraram resultados auxiliando na delimitação das unidades. A imagem SRTM foi o principal produto dessa aplicação pois nela contém dados altimétricos, favorecendo a delimitação das unidades do relevo por cota altimetrica. Primeiramente no software Global Mapper foi feita uma breve analise hipsométrica da imagem onde mostrou claramente as altimetrias do terreno e a partir daí a 
delimitação por cota. Para uma melhor observação do relevo, foi necessário a utilização de ferramentas do ArcGis, principalmente o ArcToolbox onde foram feitos vários processos na imagem SRTM, entre eles: Modelo Digital de Elevação (MDE), relevo sombreado, declividade com método de porcentagem e por fim o Triangulated Irregular Network (TIN). Essas ferramentas foram de muita importância para se fazer a delimitação das unidades.

Bibliografias anteriores como Souza (1988) Meireles (1991, 2012), contribuíram muito na delimitação de unidades geoambientais do Estado do Ceará, em questões de origem, dinâmica, morfologia e cotas altimétricas, que cada feição tem individualizada. No Atlas de Icapuí (MEIRELES; SANTOS, 2012) foi elaborado um mapa de componentes geoambientais da planície costeira de Icapuí (MEIRELES 2012). Esse mapa foi utilizado como base na delimitação das feições litorâneas.

O entendimento de campo local também é levado em consideração, visto que os softwares delimitam meramente as unidades de acordo com a altimetria, por essa razão, a percepção de campo para determinar as unidades é fundamental na fase de constatar se os dados produzidos por geoprocessamento estão corretos.

Para melhor compreensão da aplicação foi criado um fluxograma do passo a passo dos materiais utilizados no software ArcGis 10.4 (figura 1). O sombreamento neste caso foi usado para uma questão mais estética do produto final, causando um efeito de rugosidade do terreno. Sendo assim, mais fácil de identificar as feições morfológicas. O preenchimento de falhas é uma técnica que corrige pequenas imperfeiçoes da imagem, corrigindo informações de pixel, desta maneira, melhorando a qualidade do produto final. E por fim a declividade do terreno, foi usado um método em porcentagem que é mais detalhada e se adequou melhor a escala de trabalho. O MDE e o TIN tiveram um intervalo de confiança definido de 10 metros, possibilitando dessa forma uma melhor delimitação das unidades. 


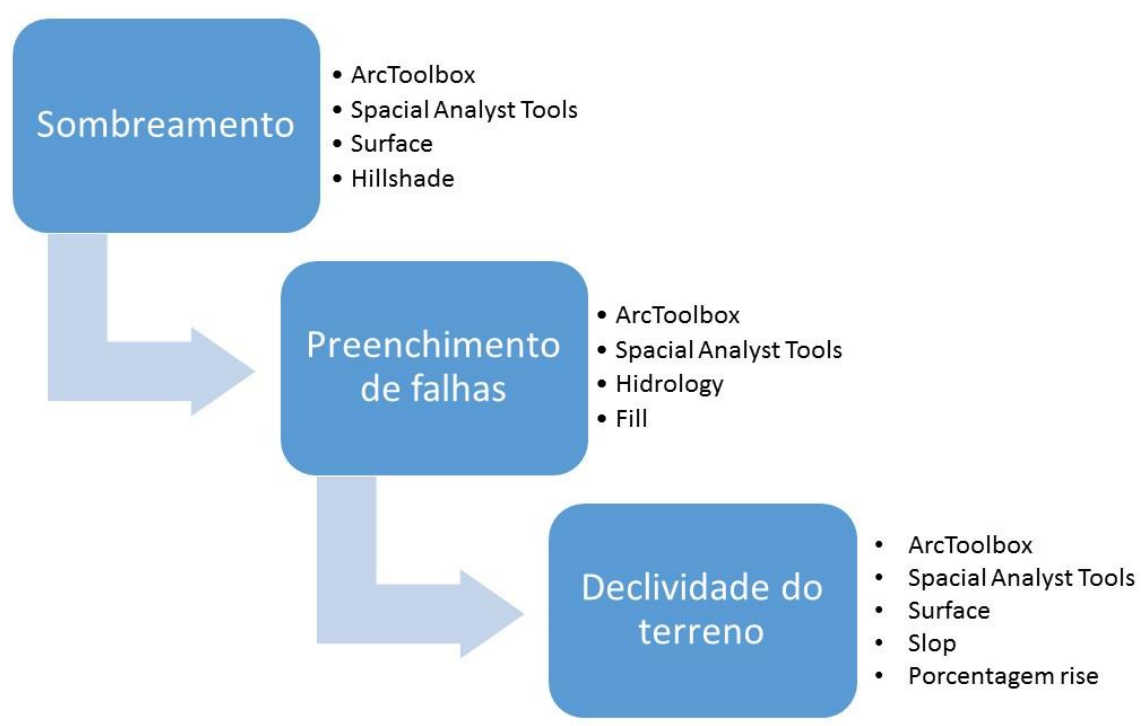

Figura 01. Fluxograma. Fonte: Vieira (2016)

Após executado esses passos e ter como resultado um MDE, TIN e Declividade do terro, foi feita uma correlação das cotas altimétricas com as morfologias descritas em bibliografias, também foi preciso uma fazer análise espaço-temporal nas imagens de satélite para constatar a dinâmica das unidades geoambientais.

Para delimitar todas as unidades, foi feito uma vetorização de cada unidade, casando informações do MDE, imagens de satélite, bibliografia e campo. Vale salientar que nessa etapa os resultados do geoprocessamento foram de grande magnitude para a delimitação das unidades.

\section{RESULTADOS E DISCUSSÃO}

Os resultados desse mapeamento foram bem satisfatórios no que diz respeito ao que foi proposto no artigo e os produtos condizem com a realidade. Precisamos salientar que para a escala utilizada uma imagem SRTM 30 metros de resolução deram conta, pois o mapeamento foi do município inteiro, porém, se o mapeamento fosse em uma escala de mais detalhes, seria preciso uma imagem com resolução espectral mais detalhada.

$\mathrm{Na}$ análise de declividade figura 02 - imagem 1 ficou bem expressivo a diferença altimétrica entre a cota mais alta e a cota mais baixa, essa linha vermelha no mapa delimita o tabuleiro prélitoraneo, que hora se mostra no relevo como falésias vivas ao se encostar no mar, e hora se mostra no relevo como paleofalésias dentro do continente. Também ganham destaque os terraços marinhos que estão em cotas altimétricas muito baixas, e as dunas móveis que chegam a ultrapassar a cota de 70 metros de altitude. O Modelo Digital de Elevação com um sombreado por baixo, evidenciando a rugosidade do relevo, mostra claramente essas diferenças altimétricas figura 02 - imagem 2, nele 
podemos observar os campos de dunas fixos e moveis, o relevo levemente ondulado da formação barreiras, a linha bem delimitada do tabuleiro pré-litoraneo, a planície fluvial do Rio Arrombado, e os terraços marinhos.

Por fim o último recurso utilizado foi o TIN mapa 01 , modelo de triangulação que permite a ligação do segmento central de cada pixel, assim, aproveitando cada informação altimetrica do pixel, porém, no TIN, observamos que em Icapuí algumas feições foram generalizadas como exemplo os terraços marinhos. O TIN foi feito a partir da extração de curvas de nível da SRTM.

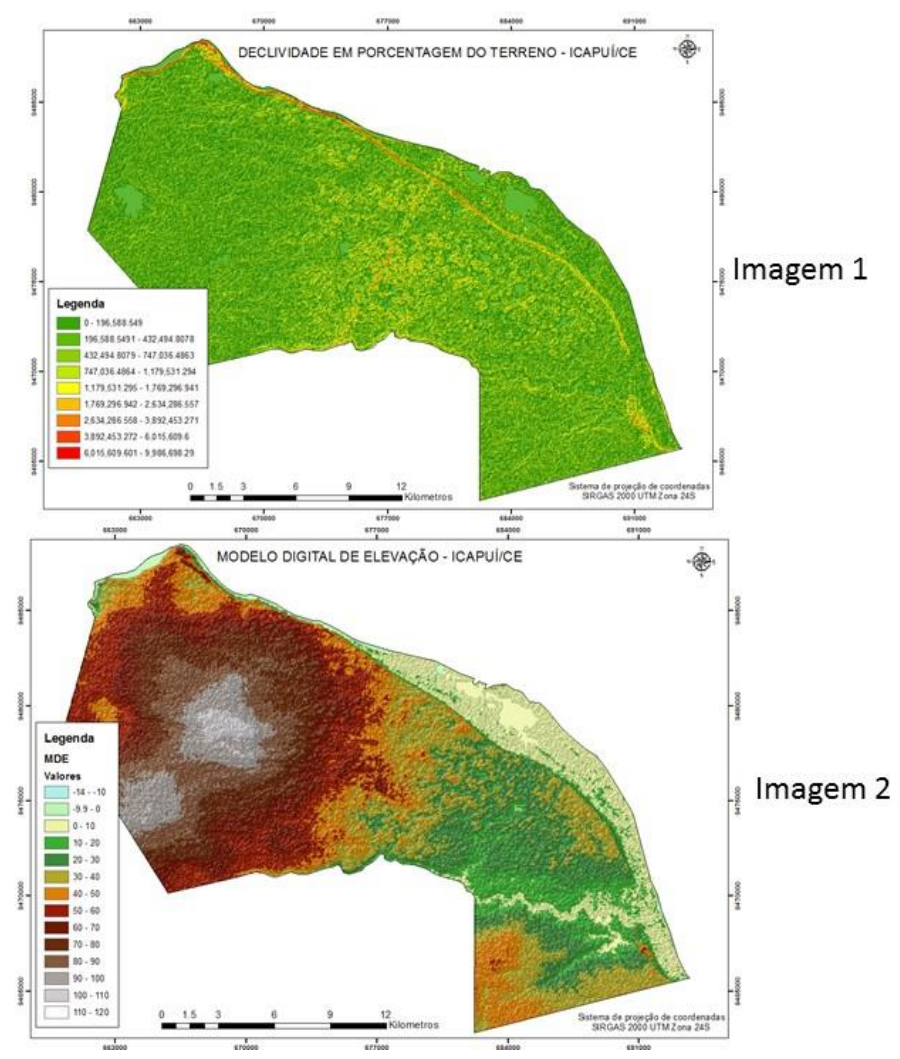

Figura 02. Mapa em porcentagem do terreno (imagem 1), Modelo Digital de Evolução (imagem 2). Fonte: Vieira (2016) 


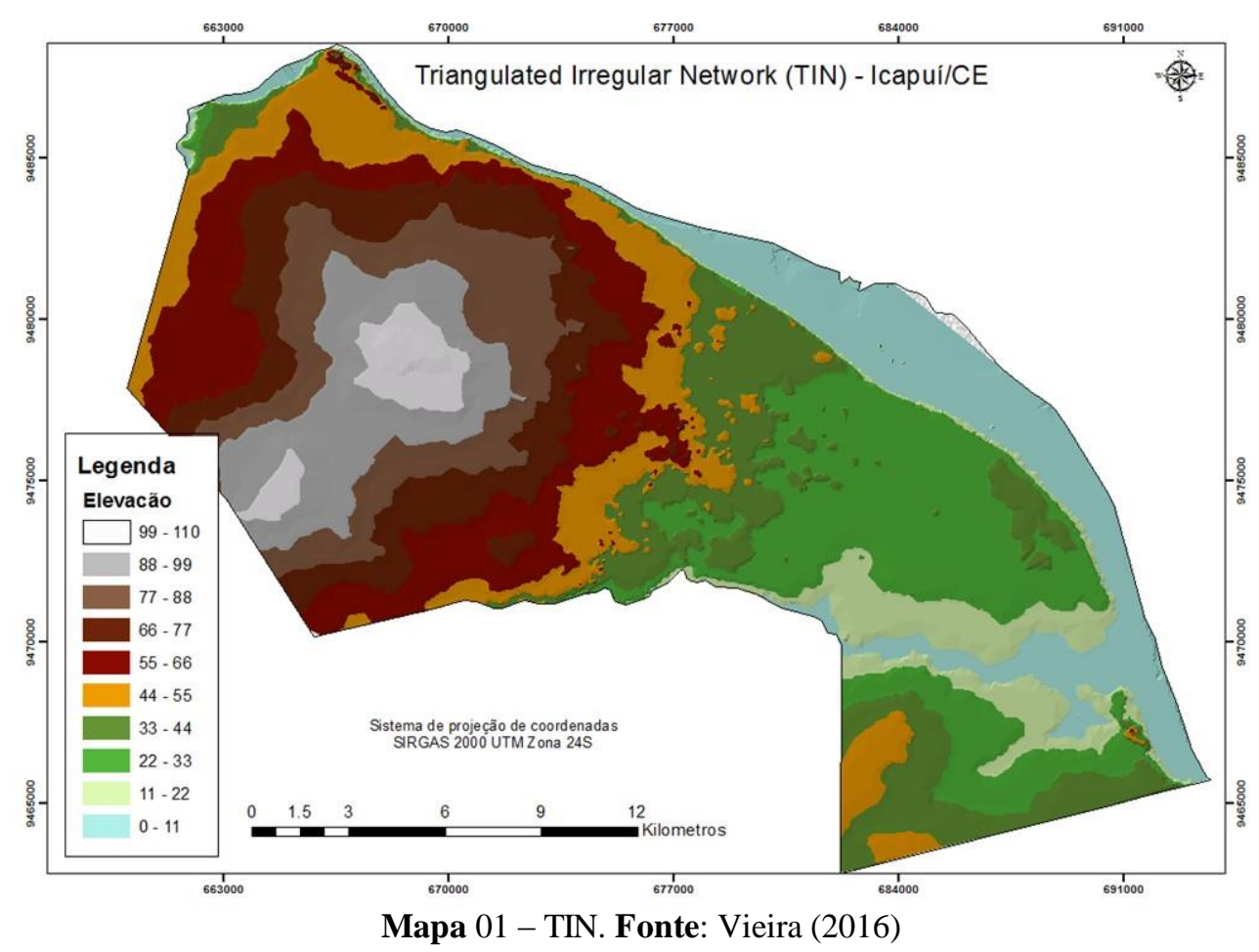

Para a delimitação correta das unidades ambientais foi feito um quarto mapa, sistematizando todos os dados obtidos em geoprocessamento, sensoriamento remoto, levantamento bibliográfico e conhecimento de campo. Foi elaborado um SIG, possibilitando a criação dos shapefiles a fim de delimitar todas as feições mapa 02.

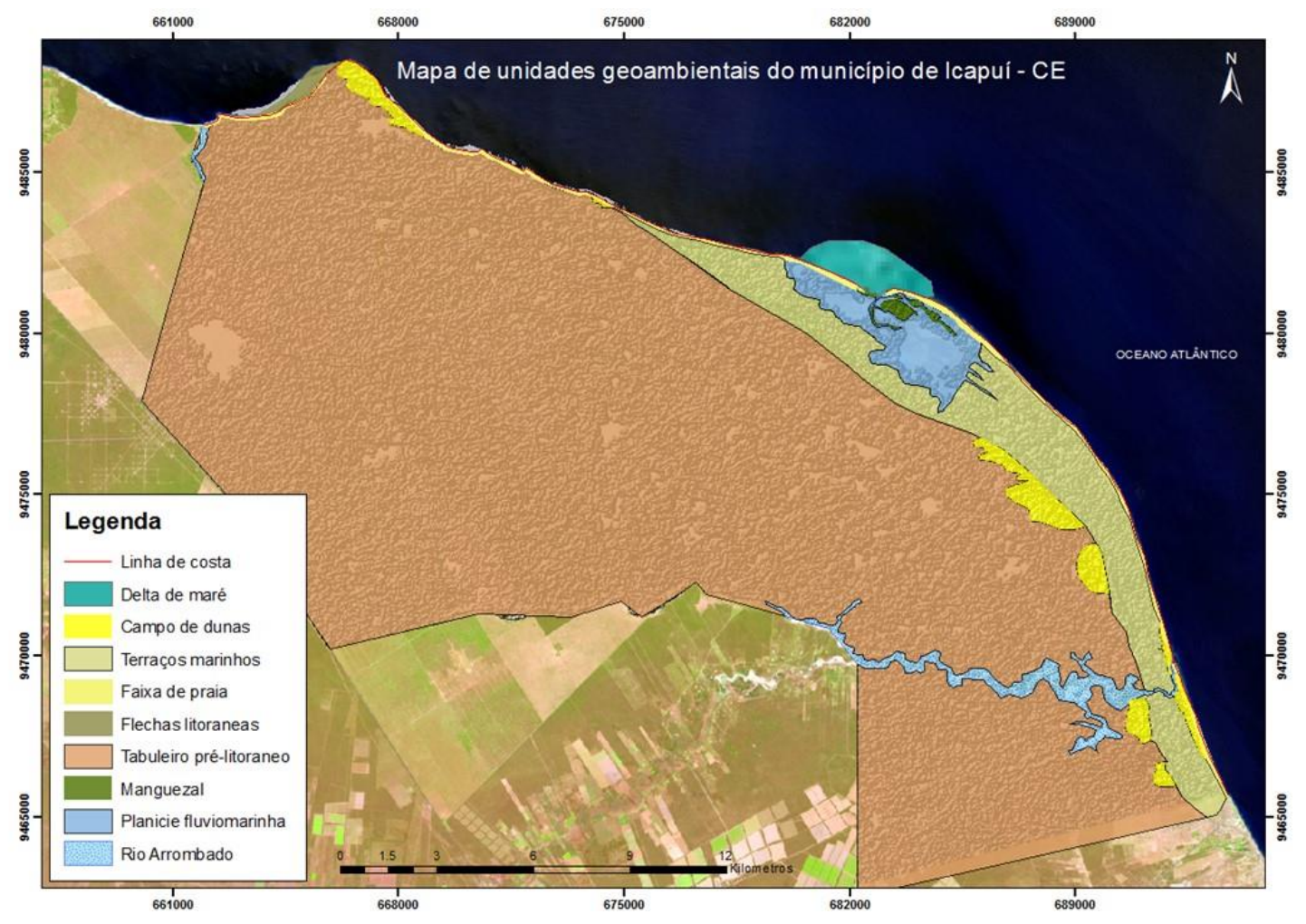

Mapa 02. Unidades Geoambientais de Icapuí. Fonte: Vieira (2016) 


\section{CONSIDERAÇÕES FINAIS}

Após todas essas analises concluímos que o geoprocessamento, alinhado com a disponibilidade desses produtos cartográficos são uma importante ferramenta nos estudos ambientais. No nosso caso em especifico a imagem de radar foi muito útil e foi determinante na delimitação das unidades. Porém, não podemos deixar de comentar que para pequenas morfologias, a resolução espectral da SRTM não foi suficiente e teve que ter auxilio de imagens com resolução maior. Também não podemos deixar de usufruir os mecanismos de campo e levantamento bibliográficos que auxiliam na contestação dos resultados obtidos por geoprocessamento. É preciso salientar que é necessário um conhecimento prévio do local para ser aplicada essa metodologia de delimitação de unidades geoambientais.

\section{REFERÊNCIAS}

MEIRELES, A.J.A. Mapeamento geológico/geomorfológico da planície costeira de Icapuí, extremo leste do Estado do Ceará. Diss. Mestrado, Centro de Tecnologia, Departamento de Geologia da Universidade Federal de Pernambuco - UFPE. Recife, 1991, 178p. il.

MEIRELES, A.J.A.; ARRUDA, M.G.C,; GORAYEBE, A. et al. Integração dos indicadores geoambientais de flutuação do nível relativo do mar e de mudanças climáticas no litoral cearense. Revista Mercator, v.8, p.109-134,2005.

MEIRELES, Antônio Jeovah de Andrade. Atlas de Icapuí / Antônio Jeovah de Andrade Meireles, Ana Maria Ferreira dos Santos. - 1. Ed. - Fortaleza, CE : Editora Fundação Brasil Cidadão, 2012.

MEIRELES, Antônio Jeovah de Andrade. Geomorfologia costeira: funções ambientais e sociais. Fortaleza : Edições UFC, 2012.489p.

SOUSA, D.C. 2003. Litoestratigrafia e deformação Cenozoica na região de Icapuí, Ceará, e implicações para a estrutura- ção de campos de petróleo na borda ocidental da Bacia Potiguar (NE do Brasil). PPGG/UFRN, Tese de Doutorado, 192p.

SOUZA, M.J.N. Contribuição ao estudo das unidades-morfoestruturais do Estado do Ceará. Revista de Geologia, Fortaleza, v.1, p.73-91, 1988.

SOUZA, Wallason Farias de. SENSORIAMENTO REMOTO E SIG APLICADOS A ANÁLISE DA EVOLUÇÃO ESPAÇOTEMPORAL DA LINHA DE COSTA DO MUNICÍPIO DE ICAPUÍ, CEARÁ - BRASIL. 2016. 134 f. Dissertação (Mestrado) - Curso de Geografia, Universidade Federal do Ceará, Fortaleza, 2016.

Recebido em: 14/08/2016

Aceito para publicação em: 01/10/2016 